\title{
Simbolismos infantis e a mágica dos contos: uma compreensão piagetiana
}

\author{
Maria Thereza Costa Coelho de Souza \\ Universidade de São Paulo - São Paulo, SP, Brasil
}

\begin{abstract}
Resumo
O objetivo deste texto é discutir as interpretações que crianças oferecem para contos populares, segundo a teoria de Jean Piaget. É conhecida a importância dada pela psicanálise aos símbolos e à simbolização, os quais permitem que encontremos sentidos para sentimentos, situações de vida e, sobretudo, no caso da criança, angústias ligadas ao desenvolver-se. Este seria o alívio trazido pelos contos de fadas. Ao estudar como as crianças concebem a realidade, Piaget destacou o pensamento mágico-fenomenista, o qual interfere nas crenças infantis e na compreensão da mágica no âmbito das interpretações realizadas por crianças mais jovens. Serão apresentadas pesquisas sobre interpretações de contos populares, com crianças de quatro a onze anos, as quais indicaram que crianças mais jovens admitem sem esforço enredos mágicos e valorizam aspectos ficcionais, enquanto que crianças mais velhas apontam a impossibilidade real das situações mágicas e valorizam aspectos reais, o que está relacionado ao seu desenvolvimento psicológico. A compreensão da mágica parece ser influenciada também pelas valorizações advindas do contexto cultural do grupo em que vivem, o que foi observado em pesquisa realizada em cooperação com a Universidade de Lausanne, Suíça, com crianças brasileiras e suíças de nove anos de idade.
\end{abstract}

Palavras-chave: Mágica, Piaget, Cultura, Afetividade.

\section{Children symbolisms and the magic of tales: a Piagetian understanding}

\begin{abstract}
The aim of this paper is to discuss children's interpretations of popular tales according to Piaget's theory. It is known that psychoanalysis gives great importance to symbolization and symbols, which allows people to find meanings to feelings, life situations and, mainly for children, distresses linked to development. This would be the relief provided by fairy tales. When Piaget studied how children perceive reality, he pointed out the magic-phenomenalistic thought, which interferes on children's beliefs and understanding of magic in the domain of interpretations performed by younger children. Researches regarding interpretations of popular fairy tales, conducted with children from 4 to 11 years of age, showed that younger children admitted, without effort, magical plots and valued fictional aspects, while older children expressed the real impossibility for magical situations and valued real aspects. These elements can be associated to their level of psychological development. The understanding of magic also seems to be influenced by the cultural context of the groups in which children live, as shown in a research carried out in cooperation with the University of Lausanne, Switzerland, with children of nine years of age.
\end{abstract}

Keywords: Magic, Piaget, Culture, Emotions.

Endereço para correspondência: Avenida Prof. Mello Moraes, 1721, Cidade Universitária. São Paulo/SP, Brasil. CEP: 05508-030. E-mail: mtdesouza@usp.br. Telefone: +55 1130914355.

Sobre a autora:

Maria Thereza Costa Coelho de Souza - Professora Associada. Departamento de Psicologia da Aprendizagem, do desenvolvimento e da personalidade do Instituto de Psicologia da Universidade de São Paulo. 


\title{
Los simbolismos infantiles y la magia de los cuentos: una comprensión piagetiana
}

\begin{abstract}
Resumen
El objetivo de este texto es discutir las interpretaciones que los niños dan a los cuentos populares, según la teoría de Jean Piaget. Es conocida la importancia dada por el psicoanálisis a los símbolos y a la simbolización, los cuales permiten que encontremos sentidos para sentimientos, situaciones de vida y, sobre todo, en el caso del niño, angustias ligadas al desarrollo. Éste sería el alivio traído por los cuentos de hadas. Al estudiar cómo los niños conciben la realidad, Piaget destacó el pensamiento mágico-fenomenista, el cual interfiere en las creencias infantiles y en la comprensión de la magia en el ámbito de las interpretaciones realizadas por niños menores. Serán presentadas investigaciones sobre interpretaciones de cuentos populares, con niños de cuatro a once años, las cuales indicaron que niños menores admiten sin esfuerzo tramas mágicas y valorizan aspectos ficcionales, mientras que los niños mayores apuntan la imposibilidad real de las situaciones mágicas y valorizan aspectos reales, lo que está relacionado a su desarrollo psicológico. La comprensión de la magia parece ser influenciada también por las valorizaciones advenidas del contexto cultural del grupo en que viven, lo que fue observado en una investigación realizada en cooperación con la Universidad de Lausanne, Suiza, con niños brasileros y suizos de nueve años de edad.
\end{abstract}

Palabras clave: Magia, Piaget, Cultura, Afectividad.

\section{Introdução}

Este texto pretende discutir as relações entre a compreensão da mágica que está presente em contos populares (de fadas e maravilhosos) e o tipo de interpretação realizado por crianças de diferentes idades, à luz da teoria piagetiana do desenvolvimento psicológico, quanto aos aspectos cognitivos e afetivos. A mágica dos contos será abordada por meio da apresentação do tema dos simbolismos e dos processos de simbolização no desenvolvimento infantil no que se refere à abordagem baseada em conceitos da psicanálise e, especialmente quanto aos conceitos de Piaget sobre o tema, para apontar principalmente como este autor buscou compreender a mágica em termos da qualidade do pensamento da criança.

A novidade que ora se apresenta é incluir também concepções do mesmo autor sobre a afetividade da criança, necessariamente presente nas interpretações dos contos. Para ilustrar o olhar piagetiano, serão apresentados alguns dados de pesquisas que utilizaram contos para a investigação do pensamento e da afetividade, com base na teoria de Piaget e, especialmente, um breve recorte de estudo realizado com crianças de nove anos de idade, no Brasil e na Suíça, no âmbito de cooperação científica entre o Instituto de Psicologia da USP e a Faculté des Sciences Sociales et Politiques da Universidade de Lausanne, Suíça. Com isso, pretendemos demonstrar que a teoria de Piaget pode permitir reflexões sobre a compreensão da mágica que se apresenta nos contos populares (de fadas ou maravilhosos).

\section{Mágica, símbolos e simbolização}

O psicanalista Bruno Bettelheim (1980) apontou que a importância dos símbolos e da simbolização no desenvolvimento psicológico é a de permitir que todos nós encontremos sentidos para nossos sentimentos, situações de vida e, sobretudo, no caso da criança, angústias ligadas ao desenvolver-se. Ou seja, todos nós buscamos significados em nossas vidas tanto para os aspectos do percurso natural, quanto para os problemas com os quais nos defrontamos neste caminho. A aquisição de uma compreensão segura sobre a própria vida proporcionaria, então, um desenvolvimento psicológico no qual as angústias naturais do crescimento poderiam ser enfrentadas como parte da vida, e não como tragédias e rupturas de sentido.

Para Bettelheim, este seria o alívio trazido pelos contos de fadas, que apresentam magicamente os desafios e superações da vida e do desenvolvimento. E ainda; o fato deste tipo de história não oferecer figuras ambivalentes seria de grande valia para as crianças, em especial as mais jovens, na medida em que, ao 
apresentarem separados os aspectos bons e maus que mais tarde deverão se integrar, permitiriam que as crianças pudessem lidar com as ambiguidades. Estudos sobre as identificações e valorizações que crianças fazem de personagens dos contos indicam que as crianças pequenas que se identificam com o herói o fazem para se ligarem à sua pessoa, e não propriamente à qualidade que representa (bondade, por exemplo).

A identificação com a qualidade (virtude) virá com o desenvolvimento cognitivo e afetivo da criança, sendo observada em crianças mais velhas. Assim, crianças mais jovens utilizam sua experiência real para suas valorizações e identificações, ao passo que as crianças mais velhas parecem se basear em critérios mais abstratos. Esta diferença permite que as interpretações dadas para os contos apresentem diferentes composições quanto aos aspectos das personagens destacados como mais interessantes e aos focos de escolhas para pensar.

Outra relação com o desenvolvimento psicológico apontada por Bettelheim é a de que o significado mais profundo do conto varia de pessoa para pessoa e de idade para idade, já que as qualidades das estruturações variam ao longo da vida e podem sofrer a influência de outros aspectos (contextuais). É por esta razão que não se deve explicar o significado do conto para a criança, o que impediria seu trabalho pessoal de elaboração. Nem tampouco se deve deixar que a criança faça isolada e sozinha este trabalho; o adulto pode e deve (segundo Bettelheim) ajudála nisso, mas nunca de maneira diretiva, evitando mensagens moralistas e com ligações diretas entre o conto e o comportamento da criança e, de preferência, permitindo que a criança apresente suas próprias versões e julgamentos.

Por este motivo, Bettelheim é totalmente contra as modificações que as versões mais modernas fazem em relação às versões originais dos contos, retirando desses passagens consideradas "fortes" ou inadequadas para crianças. Também critica as versões Disney, as quais, a seu ver, rompem com a possibilidade da criança imaginar a história usando os elementos por ela criados. Ao apresentar as histórias repletas de efeitos especiais, as versões Disney desviam a atenção da criança para aspectos nem sempre centrais. $\mathrm{O}$ mesmo faz o adulto que retira a priori a mensagem do conto inserindo-a como parte deste, impedindo a criança de extrair outros significados e mensagens.

Os argumentos do autor parecem incontornáveis e facilmente provocam aceitação da parte dos adultos, pais e educadores, que, além de lidarem com seus filhos e alunos em desenvolvimento, enfrentam os próprios processos de amadurecimento. Parece, pois, haver consenso quanto à ideia de que necessitamos de significados para nossas vidas. Mas, como obtemos esses significados? Estão já prontos e definidos pelos que antecederam o nosso nascimento? Deverão ser buscados? São construídos? Estão investidos de afetos? São definidos intencionalmente?

São muitas as teorias que se dedicam a explicar como os significados surgem em nossas vidas, qual sua gênese e quais os fatores que os influenciam. Este não foi propriamente tema dos estudos de Piaget, o qual, no entanto, esclareceu sobre os processos envolvidos na significação das ações e também do mundo, do nascimento à vida adulta. Sua teoria da inteligência testemunha o foco (e gênese) na significação das ações práticas do bebê, assim como as transformações nas estruturas da inteligência, as quais possibilitam novas significações (Piaget, 1936; Piaget \& Inhelder, 1964).

\section{Contos de fadas e simbolização}

Os simbolismos dos contos de fadas são encarados na Psicologia como responsáveis pela intermediação simbólica entre o mundo interno e a realidade. Algumas teorias focalizaram os aspectos universais dos símbolos (a teoria de Jung) e outras, os aspectos individuais (psicanálise freudiana). Teorias do campo da Sociologia estudam os símbolos presentes em contos de diferentes origens, buscando as regularidades históricas e sociais, analisando as convergências e divergências entre as narrativas. Petitat (1998), sociólogo suíço contemporâneo, em sua obra sobre o segredo, focaliza-o no contexto da mediação entre interior e exterior deslocando-o para o universo psicológico, já que o encara como um "jogo em torno de convenções sociobiológicas, sociocomportamentais e enfim sociossimbólicas" (p. 228).

$\mathrm{O}$ autor insere o segredo no universo psicológico, pretendendo entendê-lo em termos dos processos de representação e de construção do conhecimento. A partir de sua formação 
piagetiana, inicia suas reflexões discutindo a ideia de mentira, de "algo" escondido ou "a esconder", já presente na criança pequena. $\mathrm{O}$ mesmo autor discute as construções representacionais dos diversos mundos aparentes, ao lado do mundo real, apoiando-se, em grande parte, na concepção de representação de Piaget, estendendo-a ao universo da ficção. Nesse ponto, encontra na literatura dos contos fonte inesgotável de material que permite observar as relações entre o mundo real e o(s) mundo(s) ficcional(ais).

$\mathrm{O}$ autor analisa diferentes tipos de contos: contos de animais, contos maravilhosos (sem a presença das fadas), contos formulários (que apresentam uma "fórmula" de resolução), contos de fadas e, finalmente, contos "ordinários" (que são contos simples transmitidos por contadores, oralmente). Ao conduzir pesquisas sobre o que denominou "recepção" das histórias pelos indivíduos, ele criou o conceito de "Matrizes Interativas", que se apresentam em todas as narrativas e que são relativas à capacidade maior ou menor para compreender os elementos centrais das narrativas e avaliar (julgar) suas múltiplas relações. Desta maneira, as matrizes interativas se situam numa fronteira entre uma teoria sobre a reversibilidade simbólica e uma análise empírica dos contos. Cada matriz identificaria uma "família" de situações interativas e é só a partir de uma análise empírica de textos narrativos que se poderia fazer um inventário dessas matrizes e investigar como as pessoas as identificam e avaliam.

As matrizes interativas funcionariam como espaços de jogo estereotípicos que fazem parte das competências do receptor. Tais matrizes estariam presentes nos textos da mesma maneira que em nossas vidas e teriam um lado determinado pelas estruturas e outro totalmente imprevisível. Tomando como base este conceito, o autor propõe dois níveis de análise, um relativo à identificação das interações e séries de interações (compreensão primária da ação) e outro relativo à avaliação das configurações interativas (compreensão secundária da ação ou metacompreensão). Defende uma visão genética, a exemplo do modelo construtivista no qual se inspira. Sua hipótese é a de que há um alargamento no nível da compreensão primária e um estreitamento no nível da compreensão secundária conforme o desenrolar do desenvolvimento.

No texto Contes et normativité (Petitat,
2002), a ênfase é a demonstração de que os contos podem servir para ilustrar as inúmeras facetas das teorias sobre a normatividade, em especial no que se refere às interações aí apresentadas. $\mathrm{O}$ autor se baseia na categorização clássica dos contos feita por Aarne e Thompson (1961) para destacar que estas narrativas compõem uma paisagem moral que chama a atenção dos que as ouvem ou leem, expressando relações entre o uso da esperteza e da força e outras qualidades, configurando padrões de interação nos quais há julgamentos, transgressões, punições, vitórias e vinganças. Estes padrões apresentam, para Petitat, princípios de regulação.

Petitat (2002) ainda observa que o contador "popular" parece intuir as condições de desenvolvimento das crianças, criando desta forma maneiras mais simples de contar as histórias, que são mais adaptadas aos mais jovens e que, mesmo assim, apresentam regularidades e também regras mais complexas.

E acrescenta que a melhor maneira de se compreender como as narrativas mais simples são processadas por crianças é por intermédio de teorias da ação, em especial aquelas que focalizam crianças em desenvolvimento, tais como as teorias da mente. Estas, baseadas em teorias sobre o desenvolvimento cognitivo (a de Piaget, por exemplo), focalizam a capacidade para representar e simbolizar, fundamental para o processamento da literatura fantástica dos contos. No entanto, as teorias da mente, comparadas à de Piaget, antecipam a época em que isto ocorre e discorrem sobre crianças bem pequenas.

Em texto recente, Petitat (2009) retoma o objeto de estudo da sociologia da literatura (os contos) afirmando que, tradicionalmente, as pesquisas consideram que existiria um mundo de base do qual derivariam outros mundos aparentes ou virtuais, sendo as investigações pautadas na consideração de que as narrativas ficcionais têm como única fonte o mundo real. Informa já inicialmente em seu texto que partirá de pressuposto diferente: o de que haveria mundos paralelos, o mundo real e os mundos virtuais, não sendo possível afirmar que a narrativa (o texto) seja tomado da mesma maneira por todos os indivíduos que os interpretam, pois na interpretação há um jogo de relações entre os diferentes mundos (real e ficcionais).

Piaget (1978) interessou-se pela capacidade de a criança simbolizar o mundo e 
si mesmo, a partir de suas ações práticas e sensório-motoras, definindo como conceito principal a este respeito, o de representação. A primeira novidade é a construção no pensamento infantil, da imagem mental, significante privilegiado para as ações práticas, o que permite a interiorização das mesmas e, concomitantemente, a socialização do pensamento, agora representacional. Outros significantes serão usados para representar o mundo, tais como as mímicas, as palavras e os desenhos. Um dos maiores ganhos com a construção do pensamento representacional é, justamente, poder prescindir do contato perceptivo direto com os objetos, articulando agora seus representantes (significantes). É inegável a contribuição da teorização piagetiana a este respeito para o campo da formação dos conceitos, no sentido de encarálos como abstrações representativas dos objetos da realidade.

$\mathrm{O}$ que nos interessa aqui é principalmente o conceito de representação, o qual indica a substituição da presença do objeto, seja momentaneamente, permanentemente, ou até ilusoriamente. Esta substituição do objeto em si, na mente, tem a função de fazê-lo permanecer num outro nível que não é material, mas suficiente para desencadear diversos processos cognitivos e afetivos. Deste modo, a ultrapassagem da percepção direta parece ser a principal característica e vantagem da representação sobre a percepção, já que pode atuar no nível do pensamento e da imaginação. Podemos encontrar também nos escritos de Piaget $(1926$; 1978) sobre a representação do mundo e a formação do símbolo conceitos esclarecedores quanto à compreensão da mágica, presente nos contos, ligada, neste caso, a crenças mágico-fenomenistas e ao egocentrismo.

Ao investigar as crenças de crianças de diferentes idades sobre fenômenos interiores e exteriores, o autor conclui que haveria uma tendência a interpretá-los de modo artificialista, animista e mágico-fenomenista, já que o eu ocuparia, inicialmente, posição central na compreensão do universo físico e social. As crenças seriam resultados de articulações de ideias embutidas em sistemas de pensamento mais ou menos abrangentes; formas do que Freud denominou pensamento, com suas respectivas representações conscientes. Ao analisar as crenças sobre o mundo, ainda que reconhecesse as suas motivações afetivas,
Piaget privilegiou o aspecto do pensamento e sua qualidade relacionando-o com a qualidade da representação.

Além disso, apontou a eficácia do método clínico-crítico, condizente com sua epistemologia genética, para captar a natureza das crenças, já que propunha assuntos abertos e, a partir do que a criança falava, ia propondo novas questões, com o objetivo de seguir a sua orientação de pensamento e de observar as principais influências sobre esta orientação, como por exemplo, as informações oferecidas pelos adultos. Pareceu então a Piaget que o estudo das crenças poderia ser uma boa maneira de ter acesso a aspectos do pensamento infantil e da representação em desenvolvimento. $\mathrm{O}$ autor destacou ainda que as crenças infantis apresentam características gerais do pensamento, no sentido de refletirem ou uma indiferenciação entre o externo e o interno (por exemplo, ao acreditar que o sonho está no quarto ou que vem com a noite) ou uma diferenciação entre estas dimensões; e ainda, entre a coisa e o nome da coisa, ou o objeto e um de seus representantes (a palavra).

Por algum tempo em suas vidas, as crianças acreditam que os nomes são propriedades dos objetos (realismo nominal), desprendendo-se gradativamente dessas crenças. Isto demonstraria que a função semiótica enquanto capacidade de separar o objeto de seus representantes está começando a atuar, necessitando ainda incorporar os representantes como elementos que se coordenam com os objetos e entre si, e não que se confundem com eles. Uma categoria sobre crenças infantis abordada por Piaget é a relativa às crenças fenomenistas, isto é, crenças articuladas, de que os fenômenos dependem exclusivamente das vontades dos indivíduos, estabelecendo uma causalidade mágica entre os fatos.

Isso poderia estar relacionado à compreensão da mágica dos contos, por crianças mais jovens, já que são típicas das crianças até os cinco anos de idade, em média, povoando seus argumentos e suas explicações. Piaget associou-as ao fenômeno do egocentrismo, bastante estudado por ele, em vários sentidos, dos quais o que mais interessa aqui é o que se refere a transferir para as coisas e fenômenos aspectos do indivíduo, sobretudo sentimentos. $\mathrm{O}$ autor conclui sobre este assunto que o estudo das crenças permitiria conhecer a qualidade das representações, a qual também 
poderia ser observada por meio de outras expressões representacionais, como por exemplo, o desenho.

Ainda que não se detenha muito nas articulações entre sua noção de crença infantil e o conceito de crença na Filosofia, parece que Piaget está de acordo com a definição clássica de crença, ou seja, a de "um estado mental, caracterizado representacionalmente, que permite que uma proposição (verdadeira ou falsa) e seu conteúdo sejam tomados juntamente com aspectos motivacionais em direção ao controle de um comportamento voluntário." (Honderich, 1995, p. 82-83). A crença é definida como um estado cognitivo primário, diferente da percepção, da memória, do conhecimento e da intenção, podendo envolver, mais ou menos, conceitos de diferentes qualidades.

É isso que as crianças pequenas (e também os adultos) fazem ao justificarem suas teorias sobre o mundo e si mesmos. A Filosofia discute extensamente as relações entre as crenças e a verdade, aspecto que, para a perspectiva de Piaget não é relevante, sendo as crenças infantis tomadas como "boas" teorias sobre o mundo. No campo da Filosofia, devem ser destacadas as concepções de David Hume (1711-1776) sobre o papel das crenças no entendimento humano, considerando as primeiras como fruto exclusivo da experiência e da sustentação do hábito, grande gestor do comportamento humano, estando totalmente desligadas daquilo que chamou relações de ideias (Hume, 17481751/2004).

Sua posição radical foi questionada por outros autores, como por exemplo, os racionalistas. Ao separar o que denominou questões de fato e relações de ideias, separou também as crenças do pensamento demonstrativo ou intuitivo, opondo conhecimentos que podem ser obtidos pelas simples operações de pensamento daqueles que só podem ser obtidos a partir da experiência na natureza. Retomando as concepções de Piaget, verificamos que este autor, mais próximo das concepções racionalistas, colocou as crenças da criança num continuum de desenvolvimento do pensamento, que vai do pensamento pré-lógico ao lógico, com todas as operações cognitivas e emoções que aí estão inseridas.

Diretamente ligado ao conceito de crença está o conceito de imagem mental. Montoya (2005), ao apresentar o tema da representação, sintetiza e discute o conceito de imagem mental na obra piagetiana, afirmando que:

A imagem nascente como função que permite evocar objetos, acontecimentos e situações ausentes tem uma participação necessária e insubstituível no acabamento da inteligência sensório-motora, como representação figurativa dos objetos ausentes .... A constituição da imagem torna-se necessária para a interiorização dos esquemas da inteligência sensório-motora, e isso, reciprocamente .... A imagem é absolutamente necessária para a constituição da inteligência representativa ou conceptual, mas não como elemento do conceito e sim como aspecto simbólico que serve para figurar os objetos, acontecimentos e situações em suas características particulares, incluídas as regularidades repetíveis dos fatos exteriores. (p.132)

Este autor percorreu a obra de Piaget no que tange ao conceito de imagem, desde os estudos preliminares sobre a gênese da imagem (Piaget, 1923, 1924, 1936), passando pelas investigações sobre imagem, representação e operação (Piaget, 1978) e retomando a discussão sobre a imagem mental e construção do real (Piaget, 1937). E concluiu que as origens da imagem mental e do pensamento são solidárias, pois a imagem surge e passa a intervir como apoio para evocar objetos ausentes, quando os esquemas de ação começam a se coordenar mentalmente, ainda no período entre zero e dois anos (sensório-motor). Em seguida, a imagem continua a atuar no período seguinte, o pré-operatório, ainda que mantenha o seu caráter estático, o que a impede de figurar movimentos, por exemplo. Piaget afirmou que a imagem atua sobre as operações mentais e reciprocamente e que são essas últimas que tornam a imagem flexível e capaz de figurar as transformações porque se torna também antecipatória. Isto significa que estudos sobre representações, incluindo as de contos populares, podem permitir o acesso ao desenvolvimento psicológico, cognitivo e afetivo.

\section{Interpretações de contos e pensamento mágico}

Pesquisas de De Souza (2007) sobre interpretações de contos populares, com crianças de quatro a onze anos, indicaram formas diferentes de interpretar o aspecto 
mágico dessas histórias: crianças mais jovens admitiram, sem esforço, ações e enredos mágicos, superpondo ficção e realidade; enquanto crianças mais velhas tenderam a fazer observações sobre a impossibilidade real das situações mágicas, as quais são toleradas apenas no contexto mágico dos contos de fadas. Não foi raro encontrar respostas fornecidas por crianças de 5/6 anos que expressavam total aceitação do fato do lobo mau (na história do Chapeuzinho Vermelho) ter engolido a vovó e a menina sem que elas morressem em sua barriga, pois "lá havia ar" ou "porque ele não as mastigou" ou "porque ele as engoliu inteiras". Já crianças a partir dos nove anos, em média, admitiam que isto pudesse acontecer por ser um conto de fadas, ainda que fosse impossível na realidade.

Diferenças dessa natureza demonstram claramente, a nosso ver, como as interpretações de histórias revelam aspectos característicos dos níveis de desenvolvimento psicológico em que as crianças se encontram. Estudos que focalizaram, em especial, os aspectos de personagens de contos mais valorizados (interessantes) por crianças de diferentes idades parecem confirmar a tendência de que quanto mais jovens são as crianças, mais valorizam elementos sensoriais e concretos, tais como a pele da menina ou sua voz (no caso de Chapeuzinho Vermelho) e as habilidades físicas (no caso da gata que sabe saltar bem alto, na história O Senhor Lobo e a Senhora Gata).

As crianças mais velhas, ao contrário, valorizam mais aspectos abstratos e ligados ao caráter, tais como a coragem, a esperteza (da gata) e a generosidade (da menina, da história As Moedas-Estrelas). Os indicadores citados parecem conduzir à conclusão geral de que crianças mais jovens aceitam a mágica dos contos como se fosse realidade, enquanto que crianças mais velhas a admitem porque está inserida em contextos de "faz-de-conta".

Resultados de pesquisas sobre interpretações de histórias permitem retomar a teorização de Piaget (1926) de que o pensamento mágico-fenomenista, mais presente em crianças jovens, parece favorecer as interpretações da mágica dos contos, como se fosse realidade, ou, melhor dizendo, colocandoa no mesmo nível que a realidade concreta. Quando o pensamento lógico é construído, sua própria configuração e características (não contradição, por exemplo) conduzem as interpretações a buscarem apoio mais na realidade e na possibilidade de prova concreta, o que traz como consequência a admissão da mágica apenas no contexto que não é real (ficcional), e não mais do que isso.

Os dados de pesquisas sobre interpretações de histórias parecem, então, demonstrar que os aspectos da natureza humana são mais frequentemente focalizados por crianças mais velhas enquanto que as mais jovens se debruçam sobre os aspectos mágicos. Quanto aos simbolismos, é interessante notar que a sua abordagem também varia, pois, para as crianças mais jovens, o mágico é equivalente ao real; portanto, o símbolo se confunde com o que ele representa. Já para as crianças mais velhas, o símbolo e a mágica representam aspectos reais, os quais, no contexto ficcional, são permitidos, mas não se confundem.

Ainda que Piaget não associe diretamente os simbolismos a aspectos afetivos do desenvolvimento, como fez a psicanálise, é possível pensar que as valorizações afetivas ligadas às escolhas que as crianças demonstram, bem como as preferências por uma ou outra personagem dos contos, reflitam elementos de seu desenvolvimento afetivo. Isto porque, para Piaget, a afetividade está explicitamente relacionada aos interesses e preferências, e, em última análise, aos valores enquanto expansões do $\mathrm{eu}$, no sentido de indicadores para as metas de suas ações (físicas ou mentais/simbólicas) e também como elementos centrais nas relações com outras pessoas. Pesquisas que tiveram como objetivo mapear os diferentes interesses e valorizações efetuados por crianças de diferentes idades demonstraram como estes elementos podem indicar o desenvolvimento afetivo, inclusive em suas características simbólicas (Souza, 2007).

Com o objetivo de compreender as interpretações para um conto popular dos Irmãos Grimm (1989), $O$ lobo $e$ os sete cabritinhos, quanto ao que foi denominado "recepção de contos" pela equipe de pesquisadores suíços coordenada pelo Prof. André Petitat, em dois contextos diferentes (Brasil e Suíça) e esclarecer as relações entre o mundo real e o mundo ficcional (em sua faceta mágica), foi elaborada uma pesquisa em cooperação com a Faculté des Sciences Sociales et Politiques, da Universidade de Lausanne, Suíça (Petitat, de Souza, \& Raccimolo, 2010). Do lado brasileiro, esta autora elaborou pesquisa que contou com a participação de duas alunas de graduação em 
Psicologia e que obtiveram bolsas de Iniciação Científica da Fundação de Amparo à Pesquisa do Estado de São Paulo (FAPESP).

$\mathrm{O}$ objetivo foi construir um questionário para investigar elementos das interpretações que crianças de nove anos de idade faziam sobre o conto, quanto a diversos aspectos: identificação com personagens; aspectos valorizados como mais interessantes; mensagem que o conto apresentava; relação entre a história (ficcional) e a vida real. A pergunta disparadora era "O que você acha que este conto significa?". Como decorrência desta questão, outras perguntas foram apresentadas com o intuito de mapear o modo como os participantes organizavam suas interpretações (que elementos elegiam; em quantas interpretações possíveis conseguiam pensar; qual a natureza das interpretações, etc.).

Como pano de fundo para a elaboração da pesquisa, foram escolhidas a perspectiva piagetiana sobre o desenvolvimento psicológico e conceituações de Petitat sobre as relações entre o mundo real e mundo ficcional, apresentadas anteriormente. Para este texto, serão focalizadas as respostas oferecidas para a questão inicial (disparadora), com destaque para as categorias construídas a partir destas respostas. Como respostas à pergunta disparadora ("O que você acha que este conto significa?"), podemos citar alguns exemplos:

1) "Que não se deve falar com estranhos"; "Que a mãe tem que orientar os filhos quando sai";

2) "Que não se deve abrir a porta para qualquer um"; "Que o lobo é mau e vai entrar";

3) "Que é perigoso ficar sozinho em casa";

4) "Que os pais têm que preparar os filhos para as dificuldades da vida"

Não foi o foco deste estudo buscar compreender o quanto as crianças utilizavam o conteúdo da história, mas, ao contrário, destacar em suas respostas um critério ou regulador geral, o qual, para nós, estaria diretamente relacionado às suas capacidades cognitivas e simbólicas. Assim, tomando como matéria-prima as diferenças observadas entre as respostas à pergunta disparadora, foram construídas as seguintes categorias: RECOMENDAÇÃO (prescrição), ilustrada pelas respostas apresentadas em 1); ILUSTRAÇÃO (relação entre o mundo real e ficcional), indicada pelas respostas em 2) e 3); e TEMATIZAÇÃO (abstração de um tema geral a partir da história ficcional), ilustrada pela resposta apresentada em 4). Verificou-se que as crianças brasileiras e suíças tenderam mais a fazer recomendações (85\%) em suas interpretações, do que ilustrações e tematizações, mais frequentes em respostas dadas por adolescentes e adultos.

Nas duas amostras, as crianças trataram o lobo e os cabritinhos como se fossem pessoas, atribuindo-lhes características humanas e o conto como um contexto perfeitamente equivalente ao mundo real, com características concretas, como o perigo de ficar sozinho em casa e a não conveniência de se abrir a porta de casa para um estranho. Aparentemente tanto as crianças brasileiras, como as suíças, mostraram também que a compreensão da ficção é influenciada pelo contexto do grupo em que vivem; as suíças tenderam a apontar menos possibilidades de significação para a história (o que foi aferido pela quantidade de respostas possíveis que elas ofereceram à pergunta disparadora), que crianças brasileiras.

Não pudemos deixar de refletir sobre este resultado em termos dos contextos de práticas educativas em que estas crianças vivem. $\mathrm{Na}$ Suíça, de modo geral, e na cidade de Lausanne, em particular, pais não costumam deixar filhos menores de 13/14 anos sozinhos em casa, com a justificativa de que é perigoso e de que eles não saberão se cuidar. A palavra étranger, em francês, significa tanto "estrangeiro", ou seja, que não é natural daquele lugar, como "estranho", no sentido de alguém que não é conhecido. Pais explicitamente dizem a seus filhos para não falarem com estranhos, o que é facilmente percebido na convivência com famílias suíças em ambientes públicos (jardins, museus, etc.). Na cidade de São Paulo, a prática educativa parece ser diferente; filhos ficam sozinhos em casa e, para além da recomendação para não se comunicarem com estranhos, parecem desenvolver mais alternativas de ações em relação a eles, como por exemplo, buscar ajuda ao se sentirem ameaçados, irem para a casa de vizinhos, etc.

Cogitou-se que a ênfase mais acentuada para as crianças suíças na resposta "o conto significa que não se deve abrir a porta para estranhos" poderia estar relacionada à prática educacional parental em relação aos estranhos ou aos estrangeiros. No Brasil, e mais especificamente em São Paulo, além da recomendação para não abrir a porta, há outras, tais como, a de que "se alguém bater à porta e 
estiver sozinho, finja que há mais alguém com você, etc". A possível interferência das práticas educativas parentais merece investigação à parte e não era $\mathrm{o}$ foco da investigação ora apresentada.

\section{Considerações Finais}

A título de conclusão, podemos dizer que os dados das pesquisas como um todo e da pesquisa em cooperação com a Suíça, em particular, parecem indicar que, quando se trata de situações mágicas e ficcionais, crianças de diferentes idades e contextos manifestam em suas interpretações as características de seu desenvolvimento psicológico e também as valorizações emergidas de seu grupo de convivência social e cultural.

Os contos populares (de fadas e maravilhosos), se utilizados como instrumentos para a pesquisa das interpretações feitas por crianças, parecem ser muito úteis, já que desencadeiam os interesses das crianças, permitindo-lhes refletir sobre o enredo, escolher personagens, julgar suas atitudes no contexto ficcional e estender suas reflexões (mais ou menos) para o contexto real. O conto pode, então, simbolizar a realidade ou revelar temas da realidade, provocando nas crianças reflexões sobre ações e estratégias, de certa forma, preparando-as para as situações reais e concretas.

A mágica dos contos parece ter a função primordial de intermediar o trabalho mental sobre aspectos da natureza humana, os quais podem ser enfrentados no contexto simbólico, de maneira mais protegida e menos arriscada.

Por fim, a compreensão da mágica, nos diferentes momentos do desenvolvimento humano, além de fazer parte do desenvolvimento psicológico, pode promover melhores maneiras de enfrentamento da realidade objetiva e subjetiva. Os contos, plenos de mágica e de ficção, podem se configurar, então, como boas portas de entrada e acesso ao desenvolvimento de crianças do mundo contemporâneo e do século XXI.

\section{Referências}

Aarne, A., \& Thompson, S. (1961). The types of the Folk-tale: A classification. In M. Poulain (Ed.), Pour une sociologie de la lecture. Paris: Cercle de la Librairie.
Bettelheim, B. (1980). A psicanálise dos contos de fadas. Rio de Janeiro: Paz e Terra.

De Souza, M. T. C. C. de. (2007). Interpretações de histórias: afetividade $e$ inteligência em ação. 2007. Tese de Livre Docência, Universidade de São Paulo, São Paulo, SP, Brasil.

Montoya, A. O. D. (2005). Piaget: imagem mental e construção de conhecimento. São Paulo: Editora da UNESP.

Grimm, J. (1989). Os contos de Grimm. (T. Belink, Trad.). São Paulo: Ed. Paulinas.

Honderich, T. (Ed.). (1995). The Oxford companion to philosophy. Oxford. New York: Oxford University Press.

Hume, D. (2004). Investigações sobre o entendimento humano e sobre os princípios morais. São Paulo: Editora UNESP. Originais publicados em 1748 e 1751.

Petitat, A. (1998). Secret et formes sociales. P.U.F.: Paris.

Petitat, A. (2002). Contes et normativité. In A. Petitat (Ed.), Contes: l'universel et le singulier. Lausanne: Ed. Payot Lausanne

Petitat, A. (2009). Le réel et le virtuel. GenèveParis: Droz.

Petitat, A. (2002). Contes: l'universel et le singulier Lausanne: Ed. Payot Lausanne.

Petitat, A., De Souza, M. T. C. C., \& Raccimolo, Y. (2010). La pluralité interprétative, d'une culture à l'autre. In A. Petitat (Ed.), La pluralité interprétative. Aspects théoriques et empiriques (pp.5162). Paris: L'Harmattan.

Piaget,J. \& Inhelder, B. (1964). La psychologie de l'enfant. Paris: P.U.F.

Piaget, J. (1923). La pensée symbolique et la pensée de l'enfant. Archives de psychologie, 18(72), 275-304.

Piaget, J. (1924). Jugement et raisonement chez l'enfant. Neuchâtel/Paris: Delachaux et Niestlé.

Piaget, J. (1926). La représentation du monde chez l'enfant. Neuchâtel: Delachaux et Niestlé.

Piaget, J. (1936). La naissance de l'intelligence chez l'enfant. Neuchâtel: Delachaux et Niestlé. 
Piaget, J. (1937). La construction du réel chez l'enfant. Neuchâtel: Delachaux et Niestlé.
Recebido em 06 de Junho de 2012 Texto reformulado em 01 de Setembro de 2012 Aceite em 27 de Setembro de 2012 Publicado em 31 de Dezembro de 2012 